\title{
Respiratory training in Scotland
}

\section{Entry into respiratory medicine Outpatient experience}

Specialty training in respiratory medicine in the UK takes a period of at least 4 years, but the majority of trainees will spend 5 years attaining certification to practice both respiratory and general internal medicine. In order to enter a training programme, candidates will have typically been working for at least 4 years and must show they have achieved the desired competencies in foundation and core general medicine training. They must also have passed the Membership of the Royal College of Physicians postgraduate exams. The recruitment process occurs once a year and is performed nationally. Respiratory medicine is regarded as a competitive specialty.

Over the course of 5 years, trainees will be attached to a deanery that represents a geographical area and they will rotate through hospitals in this area to experience both respiratory and general medicine in a variety of environments, i.e. large teaching hospitals and smaller district general hospitals. There are four Scottish deaneries, each based around a city with associated teaching hospitals: South-east (Edinburgh), West (Glasgow), East (Dundee) and North (Aberdeen).

\section{Inpatient experience}

Respiratory medicine has close links with acute medicine and general internal medicine as a large proportion of acute admissions (30\%) have a primary respiratory pathology [1], and in many hospitals respiratory physicians will have a role in working in acute medical receiving units. Due to the high prevalence of respiratory disease, on-call shifts tend to be busy, with requests to review patients on other inpatient wards and the emergency department being common. Trainees also work within the respiratory ward managing patients and supervising junior trainees, and will be expected to perform any required pleural interventions.

There is a close working relationship with critical care and respiratory trainees are expected to spend at least 60 days working in the intensive care unit. It is also possible to combine accreditation in intensive care medicine with respiratory training.
Specialist clinics will vary depending on location, but most large hospitals in Scotland will offer an opportunity for exposure to specialist clinics in airways disease, interstitial lung disease, lung cancer, bronchiectasis, tuberculosis, pleural disease and sleep.

Some tertiary and quaternary units offer further experience in areas such as cystic fibrosis, lung transplantation, pulmonary hypertension and occupational lung disease, and it is possible for trainees to spend time in other institutions to gain exposure and experience of these specialist areas. For example, trainees in Scotland are encouraged to visit the Scottish Pulmonary Vascular Unit based in the Golden Jubilee Hospital in Glasgow to learn about the investigation and management of pulmonary hypertension. They may wish to travel to the Freeman Hospital in Newcastle, which provides Scotland's closest lung transplant service, although this unit also delivers regular satellite clinics in Glasgow and Edinburgh.

\section{Procedural experience}

As it is increasingly accepted that bedside pleural ultrasound is required for safe assessment and intervention of the pleural space [2], the procedural workload in respiratory medicine increases as nonaccredited specialists are less likely to perform such procedures. It is essential that trainees in respiratory medicine are trained quickly to perform common pleural procedures such as needle aspiration and chest drain insertion. Local anaesthetic medical thoracoscopy is also increasingly prevalent in the UK and within Scotland there are currently medical thoracoscopy services in Edinburgh, Glasgow and Dundee although it is not yet part of the curriculum requirements.

Pleural ultrasound training is mandatory and all trainees are expected to be level 1 competent upon completion of their training [1].

All trainees develop experience in flexible bronchoscopy and endobronchial ultrasound is now commonly practiced in all Scottish deaneries. Exposure to more specialist interventions such as navigational bronchoscopy, endobronchial stent
Cite as: Marshall ADL. Respiratory training in Scotland. Breathe 2016; 12: 285-286. 
and valve placement, and cryotherapy are not so frequently encountered but are available in Scotland.

Noninvasive ventilation (NIV) is commonly carried out on respiratory wards or high dependency units, and there is ample opportunity to learn about assessment, initiation and management of NIV in the acute setting. Trainees get further exposure to NIV through outpatient services directed at management of chronic ventilatory failure and management of sleep disorders.

\section{Research}

Pursuit of an academic interest is encouraged but is not essential in respiratory medicine. Trainees commonly take a 2-3 year period "out of programme" to undertake a higher research degree (MD or $\mathrm{PhD}$ ) and there are research opportunities in each of the Scottish deaneries, particularly in the South-east. It is also possible to take time "out of programme" to follow an interest in medical education, with those in teaching roles typically expected to obtain a master's degree (MSc) in medical education during this period.

\section{Teaching}

Formal teaching may vary throughout the country, although weekly departmental educational meetings are typical and most units have a regular radiology meeting to give an opportunity to discuss interesting cases or seek further opinion on radiological investigations. In Scotland there are also additional regional respiratory teaching sessions that occur every 2 months, which trainees from across Scotland attend and which typically follow an educational theme.

There is an annual Scottish Thoracic Society meeting and two meetings of the British Thoracic Society per year, a winter meeting and summer meeting with the latter being more focused on education and training.

\section{Assessment}

We are required to obtain a variety of ongoing assessments from senior clinicians that range from observation of a ward round, a clinical encounter, a practical procedure or a discussion of a case. We

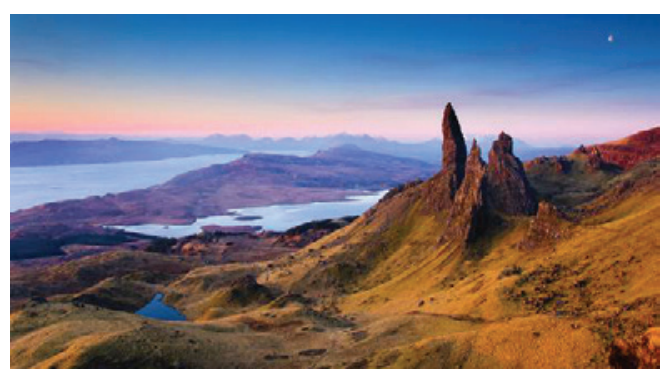

Image: @ Kenny Muir.

are also expected to obtain ongoing feedback from our colleagues in multiple disciplines (medical, nursing, clerical and allied health professionals) and patients, which are returned anonymously. All this information is logged and cross referenced with a nationally agreed curriculum [1] to provide evidence that we have gained exposure to the desired competencies. Progression through this framework is assessed on a yearly basis by a panel to ensure that trainees keep up to date.

In addition to this ongoing assessment before completion of training all trainees must have passed the knowledge based assessment "Specialty Certificate Exam" set by the Royal College of Physicians. This exam occurs once a year and had an overall pass rate of $62.4 \%$ in 2015 [3].

After completing training and providing evidence through assessments that the required competencies have been met, the trainee is issued with a Certificate of Completion of Training, which places them on the specialist register and enables them to work independently as a consultant physician in respiratory medicine in the UK.

My training in respiratory medicine has provided me with experience in three Scottish deaneries and has offered clinical exposure to a large variety of subspecialist areas and the opportunity to pursue a higher research degree. In addition to the professional benefits, outside the hospital Scotland is a place of outstanding natural beauty with easy access for those interested in outdoor pursuits. Within its cities there are an impressive array of cultural events with many music, film and arts festivals across the country with the Edinburgh Fringe being perhaps the most famous. It is no surprise therefore that Scotland remains a popular choice as a place to live and train.

\section{Conflict of interest}

None declared.

\section{References}

1. Joint Royal Colleges of Physicians Training Board. Specialty Training Curriculum for Respiratory Medicine. www.jrcptb. org.uk/sites/default/files/2010\%20Respiratory\%20 \%28amendments\%202014\%29.pdf Date last accessed June 19, 2016. Date last updated: April 17, 2015.

2. Havelock T, Teoh R, Laws D, et al. Pleural procedures and thoracic ultrasound: British Thoracic Society pleural disease guideline 2010. Thorax 2010; 65: Suppl. 2, i61-i76.
3. MRCPUK. Pass rates for the MRCP(UK) Examination and Specialty Certificate Examinations. www.mrcpuk.org/ mrcpuk-examinations/results/exam-pass-rates Date last accessed: June 19, 2016. 